This report was prepared as an account of work sponsored by the United States Government. Neither the United States nor the Departmerit of Energy, nor any of their employees, nor any of their contractors, subcontractors, or their employees, makes any warranty, express or implied, or assumes any legal liability or responsibility for the accuracy, completeness, or usefulness of any information, apparatus, product or process disclosed or represents that its use would not infringe privately-owned r.ghts.

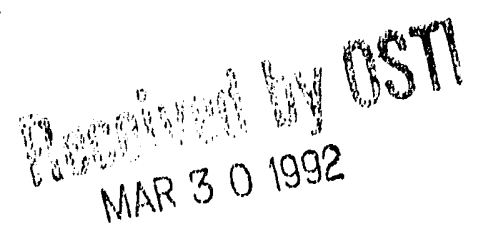




\section{Models of Natural Fracture Connectivity: \\ Implication for Reservoir Permeability}

FINAI. REPORT

for period September 15, 1989 - September 14, 1991

\section{A. Aydin}

Purdue University

West Lafayette, Indiana 47907

March 1992

Prepared for

The U.S. Department of Energy Agreement No. DE-FG02-89ER 14082

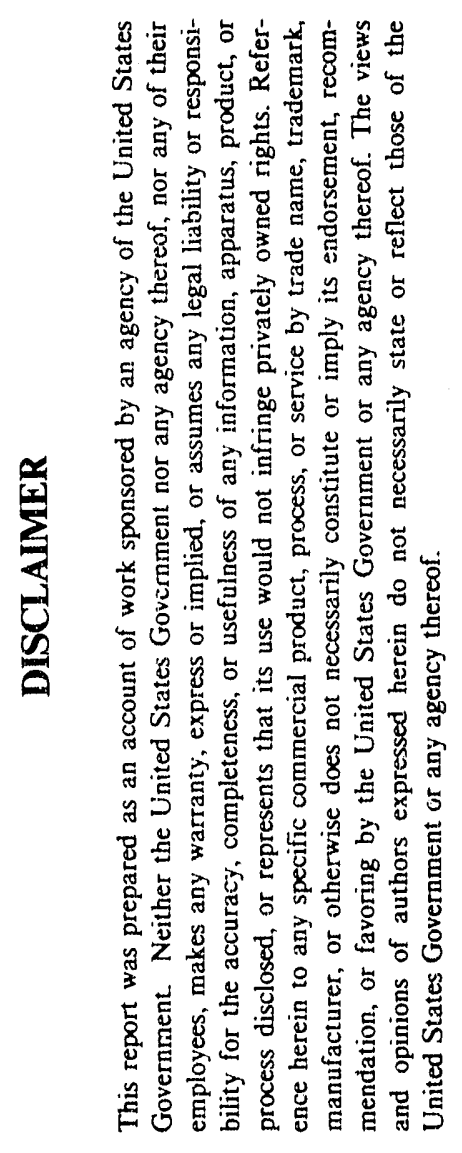


FACE SHEET (STANDARD FORM DOE F 1332.16) . . . . . i DISCLAIMATION NOTICE $\cdot$..$\quad \cdot \quad \cdot \quad \cdot \quad \cdot$ ii TITLE PAGE . . . . . . . . . . . . . iii TABLE OF CONTENTS . . . . . . . . . . . . iv ABSTRACT . . . . . . . . . . . 1

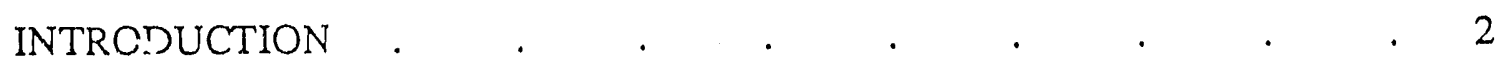

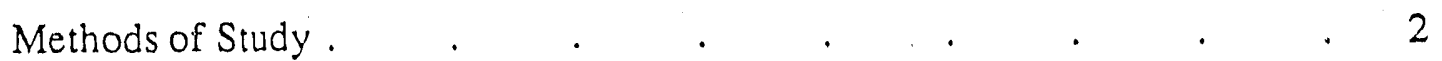

Ultimate Objectives of the Project . . . . . . . . 3 ACCOMPLISHMENTS TO DATE . . . . . . . . 3

Summary of Research Accomplishments at Purdue University . . . . 3

Theses, Papers, Manuscripts, and Abstracts from Research at Purdue University 5 Invited Talks by the P.I. Using Results from the Research at Purdue University 6 Graduate Students Supported by the Project and Their Present Employment . 6

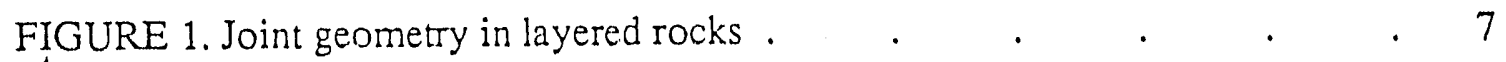
FIGURE 2. Fractures associated with shearing along interfaces . $\quad$. $\quad 8$ FIGURE 3. Joint geometry in layered rocks with sheared interfaces a $\quad$. 9 ATTACHMENTS 
We have investigated common mechanisms responsible for fracture connectivity (or lack thereof) for single and multiple sets of fractures. The methods of study were based on detailed field mapping of fractures in layered sedimentary rocks, typical of producing oil and gas reservoirs and on numerical modeling of the concepts developed from the field observations. The crucial mechanisms important for connectivity have been deduced to be fracture propagation across layer interfaces with or without shearing in slightly deformed terrains in the Appalachians Plateau, central New York, and in highly deformed terrains in the Valley and Ridge province of the Appalachians in northeastern Tennessee, northwestern North Carolina and southwestern Maryland. Both of these mechanisms have been simulated by using numerical models which include fracture propagation across interfaces between dissimilar layers, and interaction between parallel faults of various scales.

Fluid transport through a single fracture or a fracture network in rock depends strongly on the nature of connections between fracture segments and between individual fractures. This study has shown that layer interfaces, particularly those with thin shale layers impede fluid flow along fractures in vertical direction, whereas additional fractures between low angle faults along the interfaces enhance it. 


\section{INTRODUCTION}

Fractures form regular, discreet, sub-parallel sets that are effective conduits for water, oil, gas, and contaminant flow in rocks. Consequently, flow fields are strongly influenced by fracture geometry (e.g., spacing, aperture, length distribution, and connectivity). The permeability tensor for a fractured rock mass can be anisotropic, varying sharply from one direction to another. Furthermore, fractures are discontinuous at various scales so the permeability along the direction of fracture oriertation can be strongly heterogeneous.

This is a cooperative project between researchers at Stanford University and Purdue University to characterize the geometry of natural fracture systems in rock and to elucidate their influence on the fracture flow. The project is a key element in a broader effort to understand the role of natural fractures in the flow of hydrocarbons, ground water, and waste in the earth's crust. This understanding is vital to the energy industry both for oil and gas producrion, ground water extraction, and chemical and nuclear waste isolation and remediation.

Methods of Study

Within isolated sedimentary layers, fracture geometry is largely controlled by mechanical interaction between adjacent fractures. In contrast, interfaces between different lithologic members of a sequence and their physical and geological properties play the most important role in controlling the geometry of fracture sets that transect many layers. Research at Stanford University dealt with fracture connectivity in single massive layers, whereas research at Purdue University focused on fracture propagation across multi-layered sequences with thin shale units, with or without shearing along the interfaces.

Field-based research on the role of interfaces in fracture propagation consisted of documenting fracture geometry and determining the kinematics of fracturing across common types of interfaces. The field data was then used to develop geomechanical models for the observed effects of interfaces on the propagation, continuity, and connectivity of fractures across rock layers with various physical properties (elastic modulii, Poisson's ratios, and fracture toughness) and loading conditions. Thus, the' integration of field observation and numerical modeling provided greatly improved conceptual basis for evaluating the geometry and the connectivity of fractures and their 
role in either improving or impeding fluid flow in typical fractured reservoir rocks such as sandstone, shale, and limestone.

\section{Ultimate Objective of the Project}

The ultimate purpose of the project is to offer a predictive tool in the form of a set of consistent geological and geomechanical relationships for the quantitative link between fracture geometry and the geological and physical parameters. Although the grant has been extended for another two years, this time to Stanford University, this report has been submitted to fulfil the requirement for closing the project carried out at Purdue University.

\section{ACCOMPLISHMENTS TO DATE}

In the past two years, research at Purdue University focused on two problems both related to vertical fracture connectivity and it's role in fluid flow. First, the influence of the undisturbed interfaces between different lithologic members (usually sandstone and shale) of a sedimentary sequence on vertical fracture propagation, and second, the influence of sheared interfaces in the form of arrays of subparallel faults (usually low angle thrust faults) in various scales on the orientation and type of the connecting fractures. Details of these efforts are given in two attachments, a reprint from the Journal of Structural Geology dealing with joint propagation across layer interfaces, and a preprint of a manuscript submitted to the American Journal of Science dealing with the nature of fractures associated with slip along the interfaces. The major results of these studies are summarized below.

\section{Summary of Research Accomplishments at Purdue University}

The first line of research at Purdue University involved a detailed study of joint propagation across interfaces between layers of similar and dissimilar lithologic and mechanical properties. Detailed field observations showed that, in layered rocks, the process of fracturing is incremental; each layer fails sequentially (Figure 1). Layers of similar properties, for example, multi-layered siltstones, fracture in such a way that segments grow in-plane across the interfaces. Thus, a sequential and in-plane growth of fractures results in a composite joint surface which is continuous geometrically and physically (Helgeson and Aydin, 1991). This continuity, however, is lost if a thin lamina or lense of shale exists at the interface. In this case, fractures stop upon reaching one side 
of the shale lamina and restart at a point on the other side, slightly out-of-plane with the previous segment (Figure 1, inset). A finite element model of an opening mode fracture propagating towards a thin layer with a greater fracture resistance shows the two highest stress concentrations, symmetric about the in-plane extension of the fracture plane on the other side of the thin, unfractured layer. Presumably, one of these maxima will be the preferred location for the fracture intiation, thereby rationalizing step-like trace geometries such as those in Figure 1. The discontinuous nature of the geometry of individual joints in layered sedimentary rocks intercalated by thin shale layers has important implications to the flow of oil, gas, water, and contaminants (Helgeson and Aydin, 1991). Obviously, a constant fracture permeability would grossly overestimate the actual average permeability along the composite fracture, which includes the effect of rather impermeable shale layers.

The second line of research at Purdue University involves a detailed description and modeling of fracture formation and propagation across interfaces that are sheared (Ohlmacher and Aydin, 1992). In this case, the type, location and orientation of fractures are controlled primarily by inhomogcneities along the shear fractures at the interface and their frictional behavior (Ohlmacher and Aydin, in preparation). There is evidence that these sheared interfaces have little or no friction especially in the presence of some shale and high fluid pressure along the interfaces. If the interfaces are inclined to the least compressive principal stress by less than 45 degrees, the opening mode fractures initiate at the inhomogeneities along one array of the interface faults, propagate perpendicular to the layer, and terminate against the next array of interface faults (Figure $2 \mathrm{~A}$ ). If the interfaces are inclined to the least compressive principal stress by more than 45 degrees, then, the opening mode fractures form parallel to the interfaces. These geometric relationships among opening mode fractures and parallel arrays of shear faults also holds for large scale structures that locally transect the interfaces (Figure 2B). However, in the case of large scale structures, it is also common that shearing fractures at low angle to the interface faults form (Figure 2C).

If fracturing takes place after the cessation of faulting along interfaces, these boundaries behave much like shale laminas described earlier, causing step-like discontinuities along younger joints as illustrated by a photograph of an outcrop on a road cut in Figure 3. Note that the vertical surface represents joints that formed at a time long , after the low angle fractures, which in part filled by precipitant subparallel to the layer interfaces, ceased to be active (Ohlmacher and Aydin, 1992). 
Theses, Papers, Manuscripts, and Abstracts from the Research at Purdue University

Theses

Helgeson, D.E., 1990, Characteristics of joint propagation in the layered sedimentary rocks of the Appalachian Plateau, central New York. M.S. Thesis, Purdue University, West Lafayette, Indiana, $75 \mathrm{p}$.

Ohlmacher, G.C., 1991, Mechanics of vein, fault, and solution surface formation in Bays Mountain, Southern Appalachians. Ph.D. Thesis, Purdue University, West Lafayette, Indiana, $210 \mathrm{p}$.

\section{Refereed Papers}

Helgeson, D.E., and Aydin, A., 1991, Characteristics of joint propagation across layer interfaces in sedimentary rocks. Journal of Structural Geology, v. 13, p. 897-911.

Ohlmacher, G.C., and Aydin, A., 1992, Progressive deformation in the Appalachian Valley and Ridge, Bays Mountain Syncline, Tennessee, USA. American Journal of Science (submitted).

Ohlmacher, G.C., and Aydin, A., in preparation, Mechanics of vein, fault, and solution surface formation in Bays Mountain, Tennessee: Implications for fault friction and the state of the stress.

Unrefereed Manuscripts

Helgeson, D.E., 1990, Characteristics of joint propagation in the layered sedimentary rocks. The Rock Fracture Project Workshop, v. 1, p. F-1 - F-5.

Ohlmacher, G.C., 1990, Vein formation and fluid migration paths in the Bays Mountain Syncline (TN), Appalachian Valley and Ridge Province. The Rock Fracture Project Workshop, v. 1, p. D-1 - D-4.

Ohlmacher, G. C., 1991, A comparison of fracture networks and fluid migration pathways from various outcrops along the Appalachian fold-and-thrust belt. The Rock I racture Project Workshop, v. 2, p. E-1 - E-9.

Cruikshank, K. M., 1991, Role of fracture localization in the formation of arches, Arches National Park, Utah. The Rock Fracture Project Workshop, v. 2, p. A-1 - A-5.

\section{Abstracts}

Helgeson, D., and Aydin, A., 1989, Use of surface features for interpretation of propagation, interaction, and intersection of joints. GSA Abstracts with Programs, v. 21, p. A64.

Helgeson, D., and Aydin, A., 1989, Vertical and lateral evolution of multiple joint sets in the Appalachian Plateau, central New York. EOS Trans. AGU, v. 70, p. 1310.

Ohlmacher, G.C., and Aydin, A., 1989, Progressive deformation in the Bays Mountain Syncline, Kingsport, TN. GSA Abstracts with Programs, v. 21, p. 68.

Ohlmacher, G.C., and Aydin, A., 1989, Mechanics of vein formation in the Bays Mountain Syncline, south-central Appalachians. EOS Trans., AGU, v. 70, p. 1367.

Ohlmacher, G.C., and Aydin, A., 1990, Fluid migration paths and high pore pressure in the Bays Mountain Syncline, Kingsport, Tennessee. GSA Abstracts with Programs, v. 22, p. A94.

Cruikshank, K. M., and A. Aydin, 1991, Fracture control of the formation of the arches at Arches National Park, Utah. EOS Tran., AGU, v. 72, p. 490. 
- Cruikshank, K. M., and A. Aydin, 1991, Fracture control of the formation of the arches at Arches National Park, Utah. EOS Tran., AGU, v. 72, p. 490.

Aydin, A., and K. M. Cruikshank, 1991, How does an arch form? GSA Abstracts with Programs, v. 23, p. A469.

Aydin, A., 1991, A mechanistic approach to understanding fracture formation and making inferences about fracture properties and locations. SEG Abstracts and Programs (Invited speaker).

\section{Invited Talks by the P.I. Using Results from the Research at Purdue University}

- Chevron Oil Fields Research Company, La Habra, California. February, 1990.

- Department of Geological and Geophysical Sciences, Princeton University, New Jersey. April 1990.

- American Geophysical Union, Spring Meeting, Special Session on the History of Fracture Flow. May 1990.

- Conference on the Fractography of Glasses and Cermica II, New York State College of Ceramics, Alfred University, New York. July 1990.

- Gordon Research Conferance on Modeling of Flow in Permeable Media, Plymouth State College, New Hampshire. August 1990.

- Workshop on Geophysical Methods for Fracture Detection, Society of Exploration Geophysicists, Houston, Texas. November 1991.

Graduate Students Supported Full Time or Part Time by the Project, Their Theses Titles and Present Employments

Diniel E. Helgeson "Characteristics of Joint Propagation in the EXXON Layered Sedimentary Rocks of the Appalachian Plateau, Central New York" (MS)

Gregory C. Ohlmacher "Mechanics of Vein, Fault, and Solution Surface Formation in Bays Mountain, Southern Appalachian" (Ph. D.) 


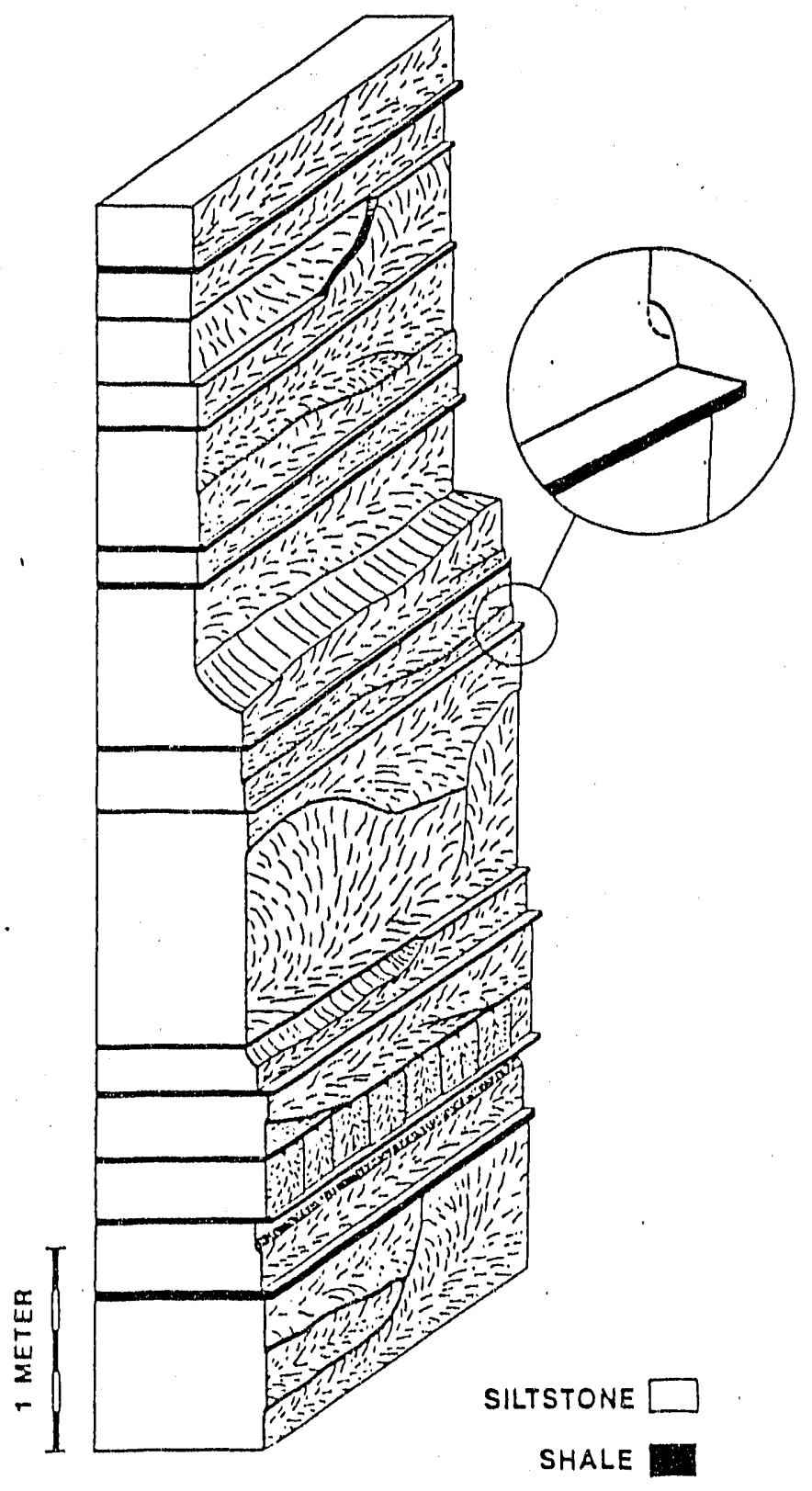

Figure 1. Joint geometry in layered rocks. A block diagram showing a large joint surface in a siltstone-shale sequence at the Appalachian Plateau, central New York. The siltstone layers are individually fractured, as indicated by each layer having its own plumose structure. Note that the joints in adjacent siltstones are out of plane with each other, giving the overall vertical joint trace a discontinuous character. 
(A)

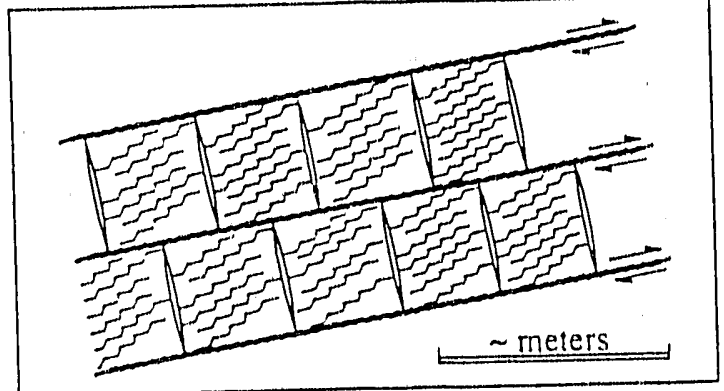

(B)

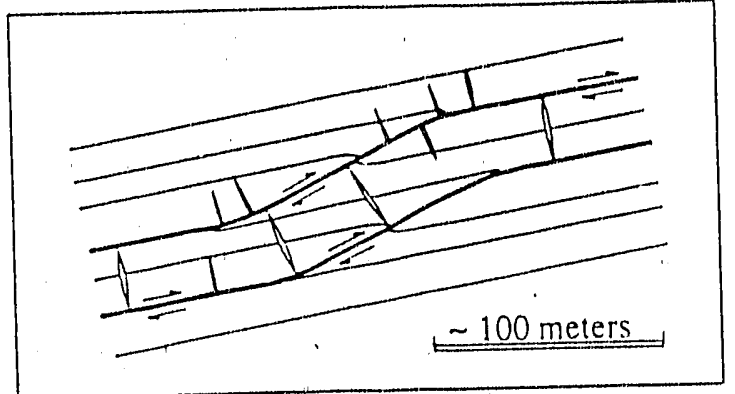

(C)

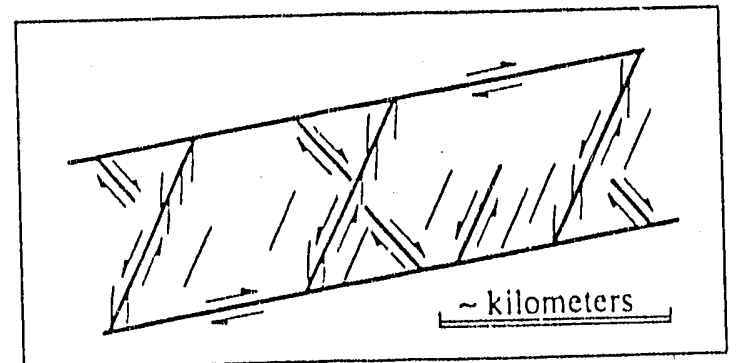

Figure 2. Fractures associated with shearing along interfaces.

Sketches of the three fracture networks recognized at Bays Mountain. (A) First network involves composite pull-apart veins and bedding-normal veins. Pressure solution surfaces and small faults within the host rock are shown as wavy lines. (B) Second network involves intermediate thrust faults and associate fault-normal veins. (C) Third network involves the larger thrust faults, normal faults, and associated faults subparallel veins. 


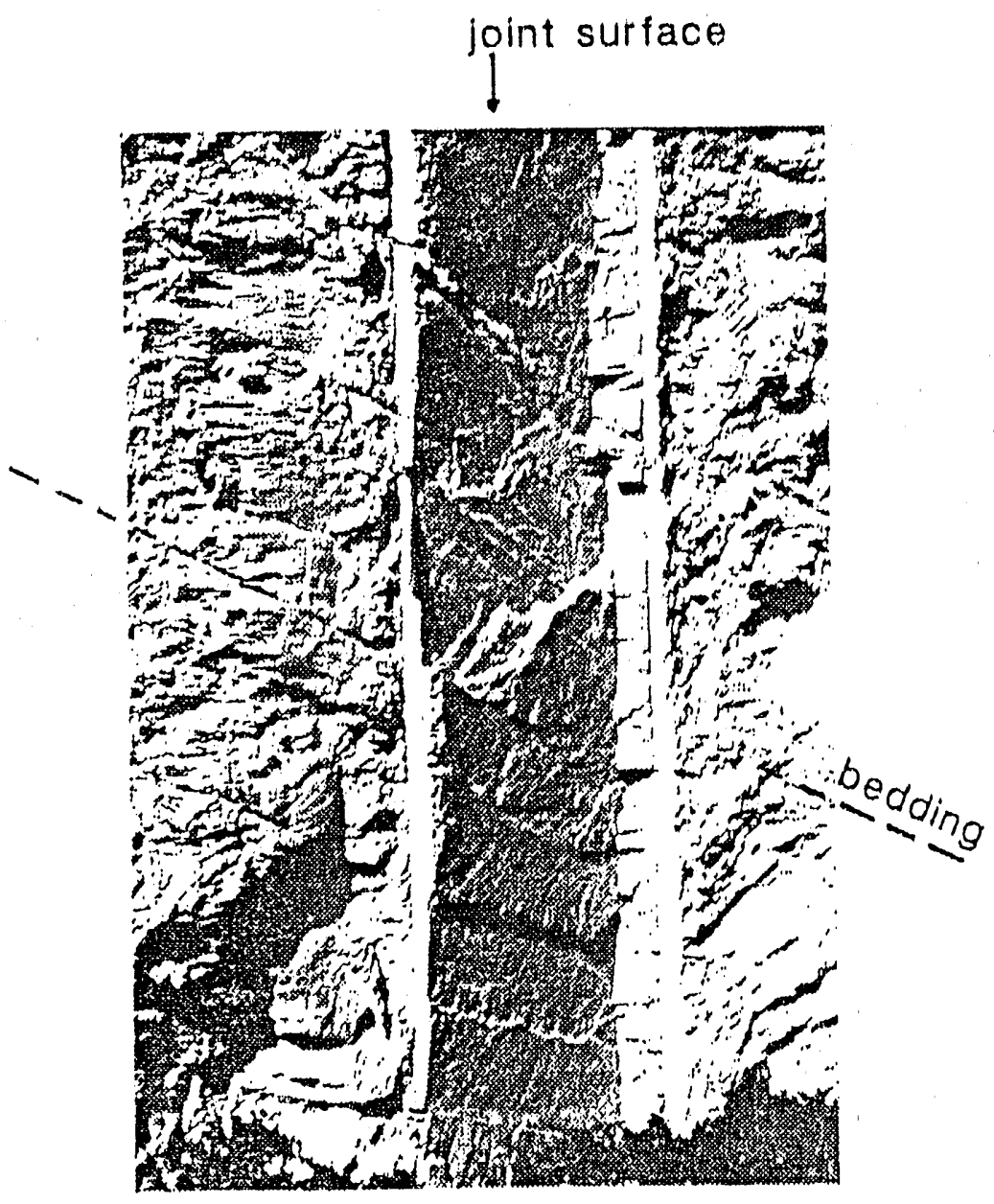

Figure 3. Joint geometry in layered rocks with sheared interfaces. Vertical joint cutting through older folds and faults at the interfaces at Bays Mountain, Tennessee. Note steps occurring at the sheared interfaces marked as "bedding". 

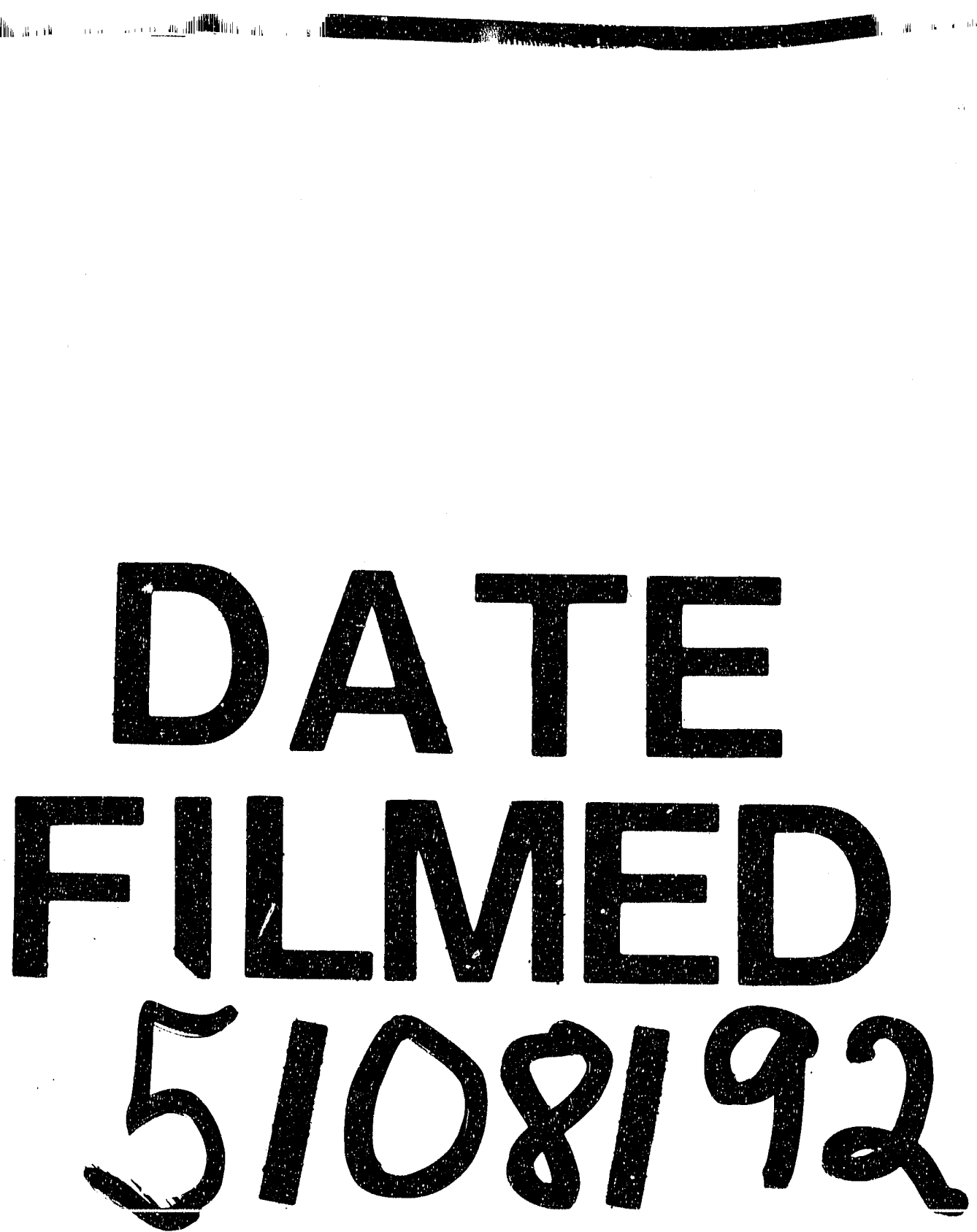
